\title{
Valuation of the Quality Attributes of Online Banking Services by Small and Medium Enterprises Engaged in International Trade
}

\author{
Parvaneh Shahnoori \\ Department of Economics, Eastern Mediterranean University, Mersin 10, Turkey and Payame Noor University, \\ Bandar Abbas, Iran \\ E-mail: pshahnoori@gmail.com \\ Glenn P. Jenkins \\ Department of Economics, Queen's University, Kingston, Canada and \\ Eastern Mediterranean University, North Cyprus \\ E-mail: jenkins@econ.queensu.ca
}

\section{Development Discussion Paper: 2018 -11}

\begin{abstract}
This study investigates the important attributes of online banking system for Small and Medium Enterprises (SMEs) and their willingness to pay for each attribute. Zero travel and waiting time, high security, and 24/7 accessibility are the key attributes for this service. The results show that SMEs engaged in international trade value online banking services significantly more than the others. Domestically focused firms value high quality service at about $\$ 163$ a month while importfocused businesses value such a service at approximately US\$646 per month. Export-intensive SMEs value high quality online services $14 \%$ further, for an average of $\$ 736$ per month.
\end{abstract}

JEL Classification: C13; C25; C93; G21; F10

Keywords: Online banking; SME; valuation; service attributes; willingness to pay; international trade; mixed logit model.

Revised paper published as: Valuation of the Quality Attributes of Online Banking Services by Small and Medium Enterprises Engaged in International Trade in the South African Journal of Economics Vol 87: 1 (2019) 


\section{Introduction}

Recent empirical evidence has indicted that increased information and communication technology (ICT) capabilities, including the ability to conduct online transactions has contributed to the internationalization of small and medium sized enterprises in Europe (Hagsten and Kotnik, 2017). Furthermore, there is strong evidence that appropriate bank services have played an important role to enable SMEs to expand their international export of goods and services. Among other banking services, online banking, have been important for the success of these SMEs to engage with export markets (Bartoli et al., 2014)

Traditional banking consumes time and effort, and, hence, it is more costly than online banking. While there are many studies that identify the important attributes of online banking for customers in developed countries, no research to date has attempted to quantify the monetary value that small and medium-sized enterprises (SMEs) place on the various attributes or characteristics of an online banking services.

This study adds to the existing literature by quantifying, in monetary terms, the economic value that these firms place on the different attributes that make up a high quality online banking services. Particular attention is given to the importance of international trade activities as a determinant of the value placed by SMEs on these services. This study shows the importance of the cost reducing role that online banking can have on the ability of SMEs to engage competitively in international trade.

Online banking brings many advantages to SMEs. Many formerly in-branch transactions can now be performed through the internet at a lower cost. These include account balance inquiries, money transfers, periodic payments, and foreign exchange transactions. The most important 
benefit of online banking is that bank accounts can be controlled by the owners or financial managers of the SMEs (Riyadh et al, 2009).

In order to perform their banking transactions using traditional banking, the owners or senior managers of SMEs have to spend time and incur transportation costs to travel to bank branches and sometimes have to wait in a line for service. Alternatively, they may hire a specific employee whom they trust to carry out these duties. If any mistakes are made, staff have to refer back to the bank in order to correct them. In principle, most of these costs can be eliminated through online banking.

The potential of online banking as an input to the growth of SMEs is evaluated here by studying firms operating in the Free Trade Zones of the United Arab Emirates (UAE), the center of trade in the Middle East. The owners of these UAE firms represent a wide range of nationalities from both developed and developing countries. In most respects these SMEs are very similar to those operating in Europe.

It is the policy of the UAE to expand its international trade sector as a catalyst for the growth of the country's economy (World Trade Organization, 2012). This is implemented through establishing free-trade zones, improving infrastructure, and supporting projects that will improve its competitive position in the international market. The UAE free trade zone was initiated in 1980 to work with the establishment of Jebel Ali free trade zone. The recent statistics show that a large proportion of the UAE's international trade is performed through the free trade zones (roughly 80 percent of its non-oil exports) (Shayah and Qifeng, 2015). These areas provide SMEs with a very fast and easy business set-up, 100\% foreign ownership, tax and tariff exemption, available space to rent offices, manufacturing or storage facilities, and modern ports for international trade 
(Freedom group, 2018). However, at the time when our field research was conducted, the banks in the UAE provided inadequate online banking services to these enterprises.

These firms operate in countries with different weekdays and different public holidays from those in the rest of the world. This can be considered a barrier to SMEs' access to international markets. Online banking helps to address this problem, as it is available 24 hours a day and 7 days a week. Another feature of online banking is its availability to business operators regardless of their location. Online banking can improve the productivity of SMEs, and this, in turn, will affect their competitiveness as exporters (Wengel and Rodriguez, 2006). Hence, these firms in this business environment constitute an ideal laboratory for measuring the value to SMEs of the quality attributes associated with online banking services.

The results indicate that a high quality online banking services has a significant monetary value to SMEs. Furthermore, the magnitude of the willingness to pay (WTP) as expressed by these SMEs is an indication of the economic value of this service to the country. In order to encourage international trading activities by SMEs it is crucial for countries to align their banking regulations so that such an efficient service is available to the SME clients of the banks

Because of the cosmopolitan nature of the operators of the SMEs in our sample and the wide range of trading activities they undertake, the results of this study are relevant to governments and banking regulators worldwide who are seeking ways to improve the business environment of this sector. The high values that these enterprises, particularly exporters, place on online banking services is further evidence of the role that banks play in facilitating the internationalization of SMEs. 


\section{Research Strategy}

To estimate the strength of business preferences toward the attributes of such banking services, one potentially could use either stated preference or revealed preference methods. Using revealed preference the willingness to pay for such a service is estimated from the observation of the coping costs that consumers incur in attempting to find a substitute for the improved service. In the case of online banking for SMEs, however, an accurate measurement of the coping costs faces a number of challenges. Some of these challenges arise when attempting to value the social value of travel time for those involved. Given the fact that many of the trips to the bank will also involve other business activities it is a challenge to sort out the coping costs associated only with the banking activities. In addition, the substitution of evening and weekend time for daytime poses the problem of also valuing non-working time. The differences in perceived risk of online versus face to face banking are also difficult to adjust for when estimating the revealed preference of the banking customer. Finally, the value that online banking creates in allowing banking customers to immediately detect banking mistakes, or internal bank fraud, is a service that simply cannot be assessed through normal revealed preference measures.

Faced with these challenges the decision was made to utilize stated preference research methods. In this study the value of a set of service attributes for online banking services is estimated using a choice experiment (CE) methodology one of the stated preference approaches for valuation. Choice Experiments (CE) have been used to study the rationality of choice behavior, with researchers using a variety of approaches to design intricate choice sets (Hensher, 2006). Using CEs, a researcher can construct a hypothetical market for a good or service. Experimental design allows researchers to generate groups of choice sets with the desired properties. Respondents are typically asked to choose between alternative goods or services with different 
levels of attributes (Balcombe et al., 2015). The attributes are the characteristics of the product or service that affect consumers' decisions. Utilizing this method allows the economic welfare effect of the attributes to be estimated. For this study, we designed different choice sets with hypothetical scenarios related to two alternative banking services. In addition to the two alternative services, we included the consumers' current banking services as the status quo alternative.

The most important attributes evaluated in this study were identified through a literature review, focus group interviews, and a pilot study. Previous researchers have identified the key attributes that people are seeking in an online banking service, such as accuracy, speed, user friendliness, convenience, accessibility, awareness, reliability, usefulness, and trust (Suh and Han, 2002; Liao and Cheung, 2002; Yousafzai et al., 2003; Sohail and Shanmugham, 2003; Akinci et al., 2004; Centeno, 2004; Lichtenstein, 2006; Eriksson and Nilsson, 2007). Other attributes that have been found to be important for consumers' satisfaction include security, convenience, cost saving, ease of use, privacy, quality of internet connection, user involvement, availability of features, pre-adoption knowledge, and creation of offline environment (Calisir and Gumussoy, 2008; Padachi et al., 2008; Poon, 2008; Vatanasombut et al., 2008; Woldie et al., 2008; Al-Somali et al., 2009; Hassanuddin et al., 2012).

Focus group interviews were held with 32 individuals in 6 of the Free Trade Zones. The participants were either financial managers of companies or bank managers. The attributes identified through these focus group interviews were: 24/7 availability, accessible from anywhere, time saving, low or no cost, easy to use, reliability, security, high speed, and instant feedback. Since the number of choice sets increases exponentially with the number of attributes and levels, we reduced the attributes to five: travel time, waiting at the bank, 24/7 accessibility, high level of security, and change in monthly charge. In the third step, we conducted a pilot study by 
interviewing 40 SME financial managers to test the selected attributes and the suitability of the attribute levels for use in our survey. The attributes selected and their levels are shown in Table 1.

Table 1 - Attributes and attribute levels of banking services

\begin{tabular}{lcl}
\hline Attribute & Number of levels & Levels \\
\hline Travel time & 4 & 0 minutes, 10 minutes, 20 minutes, 30 minutes \\
Waiting at bank & 2 & Yes, No \\
$24 / 7$ accessibility & 2 & Yes, No \\
High level of security & 2 & Yes, No \\
$\begin{array}{l}\text { Percentage change in } \\
\text { monthly account charges }\end{array}$ & 4 & $\begin{array}{l}5 \% \text { higher than current charge, } 10 \% \text { higher than } \\
\text { current charge, 15\% higher than current charge, } \\
\end{array}$ \\
\hline
\end{tabular}

In order to estimate the value of time saving related to the (two hypothetical) banking services offered, we defined four levels for travel time, two levels for waiting at the bank, and two levels for $24 / 7$ accessibility.

Travel time refers to the time that it takes for a customer to get to the bank branch. As recommended by the focus group interviews and pilot study, we considered four levels for this attribute. Waiting at bank reflects whether a customer has to wait at the bank before performing the banking transactions. The $24 / 7$ accessibility attribute indicates whether the banking services are accessible to the consumer at all times. The high level of security identifies whether the banking services are provided in a way that is confidential and not subject to fraud. The percentage change in monthly charge measures whether the consumers are willing to accept a higher monthly charge to improve the service. The choice sets include four different percentage levels of increased charges.

From the responses to these choice sets, it is possible to estimate the marginal WTP for these attributes, and the overall WTP for service packages containing alternative sets of the attributes. 
In the next step, we specified an experimental design strategy (Hensher et al., 2015). There are several strategies that can be utilized to generate choice sets. Full factorial is the most common class of design, in which generated choice sets include all possible combinations of attribute levels. In our study, if we had used full factorial treatments we would have had $\left(4^{2}\right)\left(2^{3}\right)=128$ choice sets to show to participants. However, having 128 choice sets in the stated preference part of the questionnaire would make it too long and too difficult to implement. To gain a large amount of information, one needs a sufficient number of choice sets, but having a large number decreases the quality of information because answering a long questionnaire is tedious for respondents. Therefore, there is a trade-off between the amount and the quality of the information obtained.

To reduce the number of profiles, we chose orthogonal fractional factorial as an experimental design strategy ${ }^{1}$. We generated 32 profiles using SPSS Version 20 software, and further divided the 32 treatments into four versions.

A series of choice sets were constructed using these treatment combinations so that each participant was faced with eight choice sets. These treatment combinations actually created the profiles for one service, which we called Service 1. In order to make a choice, a consumer needs at least two choices, so we included another service. To create an alternative service (service 2). we applied a shifted design technique and converted the 32 treatment combinations into four versions of a new service. ${ }^{2}$.

\footnotetext{
${ }^{1}$ Although the orthogonal fractional factorial strategy for generating the choice sets cannot convey the maximum amount of information, and it may not be D-efficient, it is likely to fulfill the expectations of the researcher and indicate the most important features of the generated choice sets (Kuhfeld et al., 1994).

2 To test and control for the potential of an ordering effect bias, Scott and Vick (1999) and Hensher et al., (2015) proposed to randomize the constructed choice sets across different versions of questionnaires. Following their recommendation to control for this potential bias we constructed 4 different versions of questionnaires each with 8 different choice sets that were randomly selected for each respondent.
} 
The two new services (Service 1 and Service 2) were included in each choice set. We further added the existing service (status quo) as an alternative for those participants who preferred their current service over the two new services. The respondents were asked to choose among these services with different levels of attributes. Therefore, each choice set had three sections: two sections for the improved services and one for the current service (status quo).

\subsection{Sample selection}

According to Orme (2010), the minimum sample size can be derived using the rule $(n t a / c)>500$, where $n$ is the sample size, $t$ is the number of choice sets faced by each respondent, $a$ is the number of alternatives, and $c$ is the largest number of attribute levels. Using this formula, the minimum sample size for our study should not be less than 83 . To increase the precision, we chose a sample of 400 SMEs, employing exogenous stratified random sampling.

To find out the number of SMEs in the UAE Free Trade Zones, we used the UAE Free Zones Directory for 2012 (Global Resources, 2012). Of the 9,976 registered companies in the Free Trade Zones, $16.7 \%$ operate in Dubai, 30\% in Jebel Ali, 3.4\% in Hamriyah, $20.3 \%$ in Sharjah, 8.2\% in Ajman, and 21.4\% in Ras Al Khaimah. We used these percentages to select our sample. Table 2 shows the number of respondents in each district. The field research for this study was conducted in October 2014. Our sampling frame is divided into six strata based on the six districts of the Free Trade Zones. 
Table 2 - Number of participants in each district

\begin{tabular}{llrrr}
\hline$\#$ & District & No. of companies & \% of total & No. of interviews \\
\hline 1 & Dubai & 1,662 & 16.7 & 67 \\
2 & Jebel Ali & 2998 & 30.0 & 120 \\
3 & Hamriyah & 339 & 3.4 & 14 \\
4 & Sharjah & 2,024 & 20.3 & 80 \\
5 & Ajman & 823 & 8.2 & 33 \\
6 & Ras Al Khaimah & 2,130 & 21.4 & 86 \\
\hline Total & & 9,976 & 100 & 400 \\
\hline
\end{tabular}

Overall, the sample represents approximately $4 \%$ of the total number of enterprises registered in the Free Trade Zones. All of the selected companies can be considered to be SMEs, as all of them employed fewer than 250 employees and their annual incomes were all less than US\$68 million ${ }^{3}$.

Among the 3,200 responses, 2,909 respondents chose the new service, while 291 preferred to stay with their current service (Table 3).

Of the 2,909 respondents who chose the new services, 2,222 (76.4\%) preferred a service with no waiting at the bank, 1,887 (65\%) preferred a service with 24/7 accessibility, 1,903 (65.4\%) preferred a highly secure service, $825(28.4 \%)$ chose a travel time of 10 minutes, $59.2 \%$ selected a travel time of 0 or 10 minutes, while the remaining 896 (30.8\%) chose a travel time of 0 .

For the cost attribute of the sample, only $9.1 \%$ of the SMEs responded by stating that they would not pay anything more than their current payment, and $90.9 \%$ were willing to pay an extra charge. Of these $90.9 \%, 28 \%$ stated that they were willing to pay $5 \%$ higher than their current

\footnotetext{
${ }^{3}$ A company with fewer than 250 employees and revenue of less than US $\$ 68$ million is considered to be an SME (World Trade Organization, 2012).
} 
monthly charges, $25 \%$ would pay $10 \%$ higher, $16 \%$ would pay $15 \%$ more, and $31 \%$ of them were willing to pay $20 \%$ more.

Table 3 -Frequency distribution for the alternatives and attribute levels

\begin{tabular}{|c|c|c|c|}
\hline & & Frequency & Percentage \\
\hline \multicolumn{4}{|l|}{ Alternative } \\
\hline & Service 1 & 1,708 & $53.40 \%$ \\
\hline & Service 2 & 1,201 & $37.50 \%$ \\
\hline & Current service & 291 & $9.10 \%$ \\
\hline Total & & 3,200 & $100.00 \%$ \\
\hline Service 1 and 2 & & 2,909 & $90.90 \%$ \\
\hline \multicolumn{4}{|l|}{ Travel time } \\
\hline & 0 minute & 896 & $30.80 \%$ \\
\hline & 10 minutes & 825 & $28.40 \%$ \\
\hline & 20 minutes & 632 & $21.70 \%$ \\
\hline & 30 minutes & 556 & $19.10 \%$ \\
\hline \multicolumn{4}{|l|}{ Waiting at bank } \\
\hline & Yes & 687 & $23.60 \%$ \\
\hline & No & 2,222 & $76.40 \%$ \\
\hline \multicolumn{4}{|c|}{ 24/7 accessibility } \\
\hline & Yes & 1,887 & $65 \%$ \\
\hline & No & 1,022 & $35 \%$ \\
\hline \multicolumn{4}{|l|}{ High security } \\
\hline & Yes & 1,903 & $65.40 \%$ \\
\hline & No & 1,006 & $34.60 \%$ \\
\hline \multicolumn{4}{|c|}{ Percentage increase in monthly charge } \\
\hline & $5 \%$ & 814 & $28 \%$ \\
\hline & $10 \%$ & 732 & $25 \%$ \\
\hline & $15 \%$ & 464 & $16 \%$ \\
\hline & $20 \%$ & 899 & $31 \%$ \\
\hline Existing service & & 291 & $9.10 \%$ \\
\hline \multicolumn{4}{|l|}{ Travel time (TT) } \\
\hline & $30 \leq T T<45$ & 134 & $48.80 \%$ \\
\hline & $45 \leq T T<60$ & 142 & $46.10 \%$ \\
\hline
\end{tabular}




\begin{tabular}{|c|c|c|c|}
\hline & $60 \leq T T<75$ & 1 & $0.30 \%$ \\
\hline & $75 \leq T T<90$ & 14 & $4.80 \%$ \\
\hline \multicolumn{4}{|l|}{ Waiting at bank } \\
\hline $\mathrm{Ye}$ & & 291 & $100 \%$ \\
\hline $\mathrm{No}$ & & 0 & $0 \%$ \\
\hline \multicolumn{4}{|l|}{ 24/7 accessibility } \\
\hline $\mathrm{Ye}$ & & 0 & $0 \%$ \\
\hline $\mathrm{No}$ & & 291 & $100 \%$ \\
\hline \multicolumn{4}{|l|}{ High security } \\
\hline $\mathrm{Ye}$ & & 291 & $100 \%$ \\
\hline $\mathrm{No}$ & & 0 & $0 \%$ \\
\hline
\end{tabular}

\section{Characteristics of the sample SMEs}

The average age of the owners is 42 . Men made up $90.25 \%$ of respondents, while $82 \%$ are married. In terms of education, $69.75 \%$ of the owners have at least one university degree. The average number of employees per firm is 11 . The average annual revenues for these firms is $\$ 1,432,472$. Out of the total number of firms, $82.25 \%$ have international trade operations, while $67.75 \%$ of all the firms import more than $15 \%$ of their inputs, and $46 \%$ export more than $25 \%$ of their turnover. The characteristics of the firms in this sample in terms of their size, and export volumes are similar to those of the Italian SMEs studied by Bartoli et al. (2014).

The characteristics of the owners of the SMEs and the companies themselves are shown in Table 4.

Table 4 - Characteristics of the sample SMEs (average and percentage)

\section{Owners' characteristics}

\begin{tabular}{ccccc} 
Age & Male & Married & University or above & \\
\hline 42 & $90.25 \%$ & $82 \%$ & $69.75 \%$ & \\
\hline Companies' characteristics & & & \\
\hline Employees & Annual revenue $(\$)$ & With foreign trade & Imports $>15 \%$ & Exports $>25 \%$ \\
\hline 11 & $1,432,472.7$ & $82.25 \%$ & $67.75 \%$ & $46 \%$ \\
\hline
\end{tabular}




\section{Analysis}

Of the five attributes, travel time and the change in monthly charge are continuous variables. The rest of the attributes, namely waiting at the bank, 24/7 accessibility, and high security, were effects coded with values of 1 and -1 . To enter the data into a spreadsheet, we coded the variables as shown in Table 5 .

Table 5 - Codes used to define the variables

\begin{tabular}{ll}
\hline Name of the variable & Explanation \\
\hline TT & Travel time (minutes): $0,10,20,30$ \\
W & Waiting at bank : $1=$ yes, $-1=$ no \\
AC $24 / 7$ & $24 / 7$ accessibility: $1=$ yes, $-1=$ no \\
HS & High security: $1=$ yes, $-1=$ no \\
CHMC & Change in monthly charge for bank account: $5 \%, 10 \%, 15 \%, 20 \%$ \\
CM & Change in monthly charge for bank account in USD \\
LMC & Log of change in monthly charge for bank account \\
TTage & Interaction of travel time and age \\
& \\
TTedu & Interaction of travel time and level of education above high school \\
& \\
TTimp & Interaction of travel time and level of imports higher than $15 \%$ \\
& \\
TTexp & Interaction of travel time and level of exports higher than $25 \%$ \\
\hline
\end{tabular}

CHMC is the percentage increase in monthly charge for bank accounts, while CM is the increase in monthly charge for bank account, in US dollars. Thus, to calculate CM we multiplied the percentages by firms' current monthly charge for bank accounts. LMC is the logarithm of change in the monthly charge. As the logarithm of 0 is undefined, in order to correct for the zerocharge cases we added $\$ 1$ to all the charges and calculated LMC as follows:

$\mathrm{LMC}=\log (\mathrm{CM}+1)$ 


\subsection{Mixed logit model}

The multinomial logit (MNL) model has been utilized in many studies, but researchers have gradually discovered that the assumption of IIA (independence of irrelevant alternatives) might not always hold. In other words, certain attributes may affect the utility of some individuals differently than they affect others. Hence, the IIA assumption that requires that an attribute affects each individual utility in the same way might reduce the accuracy of the research results. Therefore, the mixed logit (ML) model, which relaxes this restriction, has also been used (Chang and Jayson, 2011).

The assumption in the mixed logit model is that choice makers identify the features of the alternatives, evaluate the attributes of each alternative compared to the others, and select the alternative that maximizes their utility (Shaw and Ozog, 1999). Since consumers have different tastes and preferences, one should utilize the random coefficient attributes of the individuals. Thus, the utility function is:

$U_{q i}=V_{q i}+\varepsilon_{q i}=\hat{\beta}_{q} x_{q i}+\varepsilon_{q i}$

where $\dot{\beta}_{q}$ is the vector of the coefficients for the attributes that vary over individuals.

To find the probabilities using mixed logit, one must integrate the probabilities of logit over the coefficients of the density function (Train, 2009). As has been shown above, the probability of individual $q$ choosing alternative $i$ is:

$P_{q i}^{L}\left(\beta_{q}\right)=e^{\hat{\beta}_{q}^{\prime} x_{q i}} / \sum_{j} e^{\dot{\beta}_{q} x_{q j}}$

Therefore, the probability $\left(P_{q i}^{M L}\right)$ that an individual $q$ chooses alternative $i$ is calculated from the mixed logit as: 
$P_{q i}^{M L}=\int P_{q i}^{L}\left(\beta_{q}\right) f(\beta) d \beta$

$P_{q i}^{M L}=\int\left(e^{\hat{\beta} x_{q i}} / \sum_{j} e^{\hat{\beta} x_{q j}}\right) f(\beta) d \beta$

The integral can be estimated using software such as NLOGIT, which applies maximum likelihood techniques.

We first estimated an MNL model. As mentioned, above the MLN model is restricted by the assumption of IIA; to test this limitation for the model, we used the Hausman test for IIA. Since the $P$-value of the results was less than 5\%, the null hypothesis (homogenous coefficients, IIA assumption) could be rejected (Hensher et al., 2015).

To address this problem, a mixed logit model was then employed. We used the MNL model as a base for the mixed logit model, and, by changing the distribution for the coefficient of each attribute except price, we then estimated a variety of mixed logit models. Once the standard deviation of the distribution was no longer significant, we considered the coefficient to be homogeneous, and at the end of the process, the best model was chosen. In this model, the only coefficient that could be considered as a random coefficient was the travel time coefficient, which is normally distributed. ${ }^{4}$ The mixed logit model is as follows:

$V(1,2)=A S C+\left(\beta_{T T}+S D \times N\right) \times T T+\beta_{W} \times W+\beta_{A C 24 / 7} \times A C 24 / 7+\beta_{H S} \times H S+\beta_{L M C} \times L M C$

where $A S C$ stands for alternative specific constant, $S D$ is the standard deviation of travel time, and $N$ has a standard normal distribution with mean of 0 and standard deviation of 1.

\footnotetext{
${ }^{4}$ We chose the model with normal distribution for coefficient of travel time attribute rather than other distribution, as its log likelihood was the highest.
} 
Table 6 - Estimated parameters of the mixed logit

\begin{tabular}{ll}
\hline Attribute & $\begin{array}{l}\text { Coefficient } \\
\text { (Standard error) }\end{array}$ \\
\hline Random parameters in utility functions & $-0.1121^{* * *}$ \\
\hline Travel time & $(0.0089)$ \\
\hline Constant & $2.5944^{* * *}$ \\
Waiting at bank & $(0.2642)$ \\
& $-1.2833^{* * *}$ \\
24/7 accessibility & $(0.0672)$ \\
High security & $1.0138^{* * *}$ \\
& $(0.0573)$ \\
Log of change in monthly charge & $1.0822^{* * *}$ \\
& $(0.0610)$ \\
\hline Derived standard deviations of parameter distributions & $-1.4991 * * *$ \\
\hline NsTT (standard deviation of the coefficient of travel time attribute) & $(0.1048)$ \\
& \\
Number of observations & $0.1031^{* * *}$ \\
Log likelihood function & $(0.0106)$ \\
& 3,200 \\
\hline$* * * 99 \%$ Pseudo $R^{2}$ & $-1,840.4520$ \\
\hline
\end{tabular}

***99\% level of confidence

Table 6 reports on the estimates of the model using the mixed logit method. All coefficients are highly significant at the $99 \%$ level and travel time is the random coefficient variable with a different coefficient for each observation. Travel time, waiting at the bank, and the logarithm of the change in the cost of service have negative impacts on the respondent's utility, while both $24 / 7$ accessibility and a high degree of security positively impact utility. 


\subsection{Mixed logit model with interaction}

As mentioned above, the mixed logit or random parameter model allows the parameters to change over the observations. The randomness of the coefficient may be a result of the characteristics of the choice makers. To identify the cause of this heterogeneity we estimated different models with different interactions. To determine whether the individuals' characteristics affected their preferences in choosing different attribute levels, we estimated a further model that allows interactions between the random parameter, travel time, and all available sociodemographic characteristics.

Among the characteristics that affect a respondent's utility as a result of increased travel time are the person's age and level of education. The firm's characteristics that are important in affecting the respondent's valuation of travel time are the intensity of the importation and exportation conducted by the firm.

To capture the effects of these characteristics of the individual and the firm we introduced three dummy variables that were multiplied by the travel time variable. The first dummy was defined as the owners' level of education. We considered a value of 1 for the variable if the owner had a level of education above high school, and 0 otherwise. The second dummy was assigned to the level of imports of the firm as a proportion of the value of the firm's inputs. A value of 1 was considered for a level of imports higher than $15 \%$, and 0 otherwise. The third dummy was allocated to the level of exports, measured as the proportion of sales made to customers in other countries. The value of this variable was 1 for a level of exports more than $25 \%$, and 0 otherwise.

The observed utility function with the significant interactions can be expressed as:

$$
\begin{aligned}
& V(1,2)=A S C+\left(\beta_{T T}+S D \times N\right) \times T T+\beta_{W} \times W+\beta_{A C 24 / 7} \times A C 24 / 7+\beta_{H S} \times H S+\beta_{L M C} \times L M C+ \\
& \beta_{(T T \times a g e)} \times(T T \times \text { age })+\beta_{(T T \times e d u)} \times(T T \times e d u)+\beta_{T T \times \text { imports }} \times(T T \times \text { imports })+\beta_{T T \times i m p o r t s} \times(T T \times \\
& \text { exports })
\end{aligned}
$$


Table 7 shows that all the coefficients on all the variables are highly significant at the $99 \%$ or $95 \%$ level. The coefficients of all the attributes have the expected signs and the relative magnitudes of the coefficients remain quite stable across models. The parameter for the interaction between age and travel time is positive. As the age of the respondent increases, travel time becomes less important. In contrast, the coefficient on the interaction parameter between level of education and travel time is positive. Travel time has a greater negative impact on the utility of highereducated owners/managers of these firms. This is as expected, given their higher opportunity cost of time.

Table 7 - Estimated coefficients of the mixed logit model with interactions

\begin{tabular}{lc}
\hline Attribute & $\begin{array}{c}\text { Coefficient } \\
\text { (Standard Error) }\end{array}$ \\
\hline \multicolumn{1}{c}{ Random parameters in utility functions } & \\
\hline Travel time & $-0.1085^{* * *}$ \\
\hline Nonrandom parameters in utility functions & $(0.0160)$ \\
\hline Alternative specific constant & $2.6670^{* * *}$ \\
& $(0.2621)$ \\
Waiting at bank & $-1.2801^{* * *}$ \\
& $(0.0661)$ \\
24/7 accessibility & $1.0209^{* * *}$ \\
High security & $(0.0564)$ \\
Log of change in monthly charge & $1.0792^{* * *}$ \\
travel time *age & $(0.0601)$ \\
& $-1.5425^{* * *}$ \\
travel time * education & $(0.1042)$ \\
travel time * import & $0.0009^{* * *}$ \\
travel time * export & $(0.0003)$ \\
\hline Derived standard deviations of parameter distributions & $-0.0171^{* *}$ \\
\hline Standard deviation of the coefficient of travel time & $(0.0073)$ \\
& $-0.0319^{* * *}$ \\
& $(0.0089)$ \\
& $-0.0205^{* *}$ \\
& $(0.0083)$ \\
\hline
\end{tabular}


$(0.0102)$

Number of observations $\quad 3,200$

Log likelihood function $\quad-1,811.9740$

Pseudo $R^{2} \quad 0.4846$

$* * * 99 \%$ level of confidence

$* * 95 \%$ level of confidence

There is a negative relationship between a high level of imports by the company and travel time. Thus, when the level of imports is higher than $15 \%$, travel time becomes a more important factor in reducing utility. The value for the interaction parameter between the percentage of exports being greater than $25 \%$ of turnover and travel time is negative. Hence, for intensive exporters, the travel time needed to carry out banking activities has a greater negative impact on reducing the utility of the owners/managers. These two coefficients indicate clearly that time saving is relatively more important for SMEs engaged in international trade than it is for other types of SME.

The travel time coefficient for a firm with a low intensity of foreign trade is -0.1085 . While keeping the other variables constant, for a firm with a level of exports more than $25 \%$ and a level of imports more than $15 \%$, the combined coefficient on travel time is -0.1609 . The relative disutility owing to travel time experienced by the managers/owners of those SMEs that are heavily engaged in international trade is almost $60 \%$ higher than for the average of other firms.

To decide on the goodness of fit of the mixed logit model with interactions over the one without interaction terms, we applied the log likelihood (LL) ratio test.

LL ratio $=-2(\mathrm{LL}$ of the base model $-\mathrm{LL}$ of estimated model)

The LL function of this model and the previous model are $-1,811.97$ and $-1,840.45$, respectively. The LL ratio is computed as:

$\mathrm{LL}$ ratio $=-2(-1840.45-(-1811.97))=56.96$ 
The chi-square critical value with 4 degrees of freedom ${ }^{5}$ is equal to 9.488 at the $95 \%$ level of confidence, which is less than the calculated LL ratio. Thus, we concluded that the ML model with these four interaction terms is a better model.

\section{Willingness to pay}

To carry this analysis one step further, monetary estimates were made of the WTP by SMEs that are engaged intensely and not so intensely in international trade. This analysis would also identify the monetary values placed on each of the attributes of online banking by these SME firm managers. ${ }^{6}$

\subsection{Marginal willingness to pay}

The WTP by consumers for an attribute can be found by taking the ratio of their coefficient of an attribute to the coefficient of the related cost (Gronberg and Reed, 1994).

$\operatorname{MWTP}_{i}(x)=\left(\partial V(x) / \partial x_{i}\right) /(\partial V(x) / \partial C), \quad i=1,2,3, \ldots, \mathrm{I}$

Therefore,

$\operatorname{MWTP}_{i}(x)=\left(\beta_{i} / \beta_{C}\right)$

\footnotetext{
${ }^{5}$ Degrees of freedom is equal to the difference between the two models in terms of the number of parameters.

${ }^{6}$ One might wonder if the status quo bias is likely to be important in this case. In addressing this issue we have considered the following. First, only 36 respondents out of a total of 400 chose the status quo option. Second, to the degree that the status quo bias exists, it is our understanding that it would tend to cause the willingness to pay for online banking to be understated. Furthermore, we have tested to see if any of the personal characteristics of the respondents would explain why some chose the status quo. The only significant variable was the variable indicating if the firm was engaged in international trade and the coefficient had a negative value. Given, the size and significance of the empirical results it is unlikely to significantly change the substance of the results or conclusions.
} 
where $i$ refers to an attribute and $\operatorname{MWTP}_{i}(x)$ is the WTP for a change in the levels of the attributes. Marginal WTP for the attributes with two levels, namely "yes" and "no", which code as -1 and 1, is calculated $\mathrm{as}^{7}$ (Hu et al., 2004):

$\operatorname{MWTP}_{i}(x)=2 \times\left(\beta_{i} / \beta_{C}\right)$

Using NLOGIT version 3, we computed the marginal WTP for the four attributes of online banking services, along with the alternative specific constant and their associated standard errors. These values are presented in Table 8 .

Table 8 - Estimated marginal WTP for the attributes of online banking

\begin{tabular}{|c|c|c|}
\hline Attribute & $\begin{array}{c}\text { MWTP } \\
\text { function } \\
\end{array}$ & $\begin{array}{l}\text { MWTP (US\$) } \\
\text { (SE) }\end{array}$ \\
\hline Alternative specific constant & $\left(A S C / \beta_{L M C}\right) \times(\operatorname{chm} c+1)$ & $\begin{array}{c}32.8516^{* * * *} \\
(1.8928)\end{array}$ \\
\hline Travel time ( $\$ /$ minute) & $\left(\beta_{T T} / \beta_{L M C}\right) \times(\operatorname{chmc}+1)$ & $\begin{array}{l}-1.3366^{* * * *} \\
(0.1957)\end{array}$ \\
\hline Waiting at bank & $2 \times\left(\beta_{W} / \beta_{L M C}\right) \times(\operatorname{chmc}+1)$ & $\begin{array}{c}-31.5367 * * * \\
(1.8565)\end{array}$ \\
\hline 24/7 accessibility & $2 \times\left(\beta_{24 / 7 A C} / \beta_{L M C}\right) \times(\operatorname{chm} c+1)$ & $\begin{array}{l}25.1516^{* * * *} \\
(1.3549)\end{array}$ \\
\hline High security & $2 \times\left(\beta_{H S} / \beta_{L M C}\right) \times(c h m c+1)$ & $\begin{array}{l}26.5860 * * * \\
(1.4515)\end{array}$ \\
\hline
\end{tabular}

$* * * 99 \%$ level of confidence

\subsection{Compensating variation}

Individuals' choices depend on how they value their chosen product's attributes. Calculating the compensating variation $(\mathrm{CV})$ is a way to measure this valuation (Meijer and Rouwendal, 2006). CV is the change in consumer surplus (expressed in monetary terms),

\footnotetext{
${ }^{7}$ Unlike a dummy variable, which takes the value of 0 and 1 , these attributes take the value of -1 and 1 , with a difference of 2 , so the ratio should be multiply by 2 .
} 
calculated by taking the difference between two estimates of utility that are for two different levels of attributes (Morey et al., 1993; Haab and Hicks, 1997):

$V\left(x^{0}, y-\cos t+C V\right)=V\left(x^{1}, y-\cos t\right)$

where $x^{0}$ is a product with the old attributes $\left(V^{0}\right)$, and changes to $x^{1}$ with the new levels of the attributes $\left(V^{1}\right)$, and $y$ is the consumer's level of income. The value of the $\mathrm{CV}$ is the amount that equals the left and right hand sides of equation (11).

The CV here is the amount of additional monthly charge (CHMC) that keeps a consumer at its initial level of utility, hence $\mathrm{CHMC}=\mathrm{CV}$.

As previously mentioned, we used the logarithm of monthly charge, and, as the logarithm of 0 is undefined, to correct for the zero-charge cases we added $\$ 1$ to all the charges. Hence, in estimating the $\mathrm{CV}$ we must subtract $\$ 1$, as shown in equation (12).

$C V=E X P\left(\left(1 / \beta_{L M C}\right) \times\left[V^{0}-V^{1} I_{c h m c=0}\right]\right)-1$

\subsection{Welfare effect of the improved service (mixed logit model with interactions)}

To find the average value of the improved service to these SMEs, we computed the average $\mathrm{CV}$ for four different online banking service packages, using the estimated parameters.

For all four cases, we considered online banking with the travel time of zero and no waiting at the bank, but the other two attributes vary for each scenario, as follows:

1. The service is available 24 hours a day and 7 days a week, and is highly secure.

2. The service is not available 24 hours a day and 7 days a week, but is highly secure.

3. The service is available 24 hours a day and 7 days a week, but is not highly secure.

4. The service is not available 24 hours a day and 7 days a week, and is not highly secure. 
In addition to estimating the WTP for these four service packages for the entire set of firms, the firms were also sorted according the degree of their engagement in international trade and the average values calculated for travel time and the interaction variables with travel time. To do this, we grouped the firms into four categories: those with no international trade, those with some international trade, those with a level of exports more than $25 \%$, and those with a level of imports more than $15 \%$. The values of these exogenous variables for the different sets of firms are presented in Table 9. The value of the variables for waiting at the bank, accessibility, and high security attributes are 1, -1 , and 1, respectively, for all types of firm.

It is interesting to note that the average age of the respondents for the firms with engaged in international trade is just slightly higher (44 years) than that of respondents for SMEs not engaged in such trade (41years). Furthermore, the level of education is also slightly higher, on average, with $72 \%$ of respondents being college graduates versus $65 \%$ for those from the no international trading activity.

Table 9 - Average attribute levels and descriptive statistics for the current service

\begin{tabular}{lrrrrrr}
\hline & $\begin{array}{c}\text { Number } \\
\text { of firms }\end{array}$ & $\begin{array}{c}\text { Travel } \\
\text { time } \\
\text { (TT) } \\
\text { (minutes) }\end{array}$ & TT*age & $\begin{array}{c}\text { TT* } \\
\text { education }\end{array}$ & $\begin{array}{c}\text { TT* } \\
\text { imports }\end{array}$ & $\begin{array}{c}\text { TT* } \\
\text { exports }\end{array}$ \\
\hline All firms & 400 & 43 & $1,839.04$ & 29.75 & 30.00 & 19.95 \\
Without international trade & 71 & 39 & $1,528.13$ & 26.74 & 0.00 & 0.00 \\
With international trade & 329 & 44 & $1,898.20$ & 30.28 & 37.73 & 23.75 \\
With exports more than 25\% & 184 & 43 & $1,945.00$ & 30.45 & 41.80 & 42.59 \\
With imports more than 15\% & 275 & 43 & $1,895.00$ & 31.05 & 43.00 & 28.10 \\
\hline
\end{tabular}

We began the analysis by estimating the baseline utility, $V_{0}$, using equation (6) by substituting the parameter values from Table 7 along with the average attribute levels of the current service obtained from the survey and reported in Table 9. 
In order to find the welfare impact or the average WTP for the improved service, we needed to estimate the utility, $V_{1}$, with the new levels of attributes. The estimated parameters from Table 7 were again substituted into equation (6), along with the attribute levels for the four different scenarios defined above. Equation (12) was used to estimate the average value of CV for the four service packages for all the firms in the sample. These results are reported in Table 10.

Table 10 - Willingness to pay for four alternative scenarios

\begin{tabular}{lr}
\hline $\begin{array}{c}\text { Service } \\
\text { package }\end{array}$ & Estimated $\mathrm{CV}(\$)$ \\
\hline 1 & 451.07 \\
2 & 119.31 \\
3 & 110.56 \\
4 & 28.69 \\
\hline
\end{tabular}

For the entire set of firms, the probability of their choosing the first scenario, which reflects the characteristics of online banking, over the current service, is $96.5 \%$.

The computed CVs in Table 10 show that the highest average welfare effect (WTP) of $\$ 451$ per month is related to the first service package, which is full-service online banking with 24/7 accessibility and high security. For the second service package, in which 24/7 accessibility is removed, the CV decreases to $\$ 119$, or just $26 \%$ of the value of the service containing this attribute. Given that online banking is secure and does not require any travel or waiting time, the WTP for the $24 / 7$ attribute averaged over the entire set of firms is approximately $\$ 332 /$ month. It is clear that this attribute, which allows owners or managers to carry out the firms' banking outside of normal business hours if they wish, is a critical component of any service package.

The CV calculated for the third service package, which includes all the other attributes but does not include a high level of security, is only $\$ 111$, or just $24 \%$ of the service containing this attribute. Hence, given all the other attributes of online banking, the average WTP for this attribute 
over the entire set of firms is approximately $\$ 340 /$ month. Most of the value of the online service package is eliminated if it does not have a high degree of security.

Finally, the CV calculated for the final scenario, which includes only the first two attributes (zero travel time and no waiting at the bank) is only \$29 per month, or only $6.4 \%$ of the value of the full-service package. The results show that without $24 / 7$ availability or a high degree of security, $93.6 \%$ of the value of the service package is eliminated. It appears that the owners and managers believe that such an online banking service can only be used for simple transactions such as checking one's bank balance.

Using the values of the variables from Table 9, the WTP is calculated for each of the four groups of firms that are defined according to the level of their engagement with international trade. The WTP for the four service packages by each of these firm groupings is presented in Table 11 .

Table 11 - Willingness to pay for firms grouped according to their engagement in international

\begin{tabular}{crrrr}
\multicolumn{5}{c}{ trade, US dollars } \\
\hline $\begin{array}{c}\text { Service } \\
\text { packages }\end{array}$ & $\begin{array}{c}\text { Without } \\
\text { international } \\
\text { trade }\end{array}$ & With international trade & Imports>15\% & Exports>25\% \\
\hline 1 & 163.31 & 580.29 & 645.87 & 736.26 \\
2 & 42.73 & 153.70 & 171.15 & 195.21 \\
3 & 39.55 & 142.45 & 158.63 & 180.94 \\
4 & 9.79 & 37.18 & 41.48 & 47.41 \\
\hline
\end{tabular}

In Table 11, the estimated WTP for the four service packages by all groups of firms show that the priority given to the attributes in these service packages is all the same, but the absolute values change greatly. All put a high value on $24 / 7$ accessibility and high security. The proportionate reductions in value when these attributes are removed from the package are the same $(74 \%, 76 \%$ and $93.6 \%)$ for these groups as for the entire sample reported in Table 10. 
The estimates reported in Table 11 indicate the very large impact that the SME firm's engagement in international trade has on its evaluation of online banking services. Comparing the WTP of firms with no international trading activities (Table 11, column 1) with those that have some engagement (Table 11, column 2) shows that the latter place a value on all service packages that is 3.6 times greater. For firms that import more than $15 \%$ percent of their inputs, WTP increases to $\$ 645.87$ a month. This is 3.96 times the WTP of the non-trading SME firms of \$163.31 per month. For exporters, the availability of good online banking services is even more valuable. The average WTP of those SME firms exporting more than $25 \%$ of their output increases to $\$ 736.26$ per month, 4.5 times more than the non-trading SMEs. Engaging in international trade has a very pronounced impact on SMEs' WTP for online banking services. Conducting international trade involves a much larger number of time-intensive transactions, such as sending wire transfers that are more expensive if carried out at the bank branch than if processed through online banking facilities.

\section{Conclusion}

Modern banking services are critical inputs to the efficient functioning of a business and play a particularly important role in SMEs involved in international trade. Traditional banking consumes time and effort, and, hence, it is more costly than online banking. For business owners and CEOs, the opportunity cost of time is high. One of the most important attributes of online banking is that it saves time. A good-quality online banking system provides a service that requires zero travel time and waiting time, and is available 24 hours a day, 7 days a week.

The results of this study also show that security and 24/7 accessibility are key attributes. Where the scenario is changed to a situation without $24 / 7$ accessibility or one in which the services are not highly secure, the value of CV falls dramatically. 
The results of this study indicate that the benefits that trading SMEs receive from internet banking are quite substantial. For a secure and 24/7-accessible service, the average value is approximately US\$646.00 per month, or US\$7,750 per year. For export-intensive SMEs, the WTP per month increases a further $14 \%$ to an average of $\$ 736.00$ per month, or $\$ 8,832.00$ per year. For some firms, particularly those that are heavily engaged in international trade, the value of this service will be greater.

On the other hand, the cost to banks of providing this service is very modest and may even be negative, in that once the system is installed and tested, it is a cost saving for the bank (Simpson, 2002). Hence, the potential net financial and economic welfare gains are substantial. Certainly, over time, the financial cost of supplying such a service has fallen, and will continue to fall.

For developing countries wishing to expand their SME sector into areas of international trade, and be able to compete effectively with their industrialized country competitors, a key policy initiative for realizing these net benefits is to provide the complementary banking services. Banks need to be able to offer online banking services easily, and security must be assured. The results of this study provide a quantified estimate of how policies to facilitate this improvement in banking services can significantly reduce the cost of doing business by SMEs in general, particularly for those wishing to engage in international trade. 


\section{REFERENCES}

Adamowicz, W., Boxall, P., Williams, M., \& Louviere, J. (1998). Stated preference approaches for measuring passive use values: choice experiments and contingent valuation. American Journal of Agricultural Economics, 80(1), pp. 64-75.

Akinci, S., Aksoy, S., \& Atilgan, E. (2004). Adoption of Internet banking among sophisticated consumer segments in an advanced developing country. International Journal of Bank Marketing, 22, pp. 212-232.

Al-Somali, S. A., Gholami, R., \& Clegg, B. (2009). An investigation into the acceptance of online banking in Saudi Arabia. Technovation, 29(2), pp. 130-141.

Balcombe, K., Fraser, I., \& McSorley, E. (2015). Visual Attention and Attribute Attendance in Multi-Attribute Choice Experiments. Journal of Applied Econometrics, 30, pp. 447-467.

Bartoli, F., Ferri, G., Murro, P., \& Rotondi, Z. (2014). Bank support and export: evidence from small Italian firms. Small Business Economics, 42(2), 245-264.

Calisir, F., \& Gumussoy, C. A. (2008). Internet banking versus other banking channels: Young consumers' view. International Journal of Information Management, 28, pp. 215-221.

Centeno, C. (2004). Adoption of Internet services in the Acceding and Candidate Countries, lessons from the Internet banking case. Telematics and Informatics, 21, pp. 293-315

Chang , J. B., \& Jayson, L. L. (2011). Mixed Logit Models: Accuracy and Software Choice. Journal of Applied Econometrics, 26, pp. 167-172.

Eriksson, K., \& Nilsson, D. (2007). Determinants of the continued use of self-service technology: the case of internet banking. Technovation, 27, pp. 159-167. 
Global Resources (2012). Golden Rainbow: UAE Free Zones Directory. Dubai: Global Resources LLC.

Freedom Group, 2018. Which Free Zone To Choose In The UAE? Retrieved from http://www.freedomgroup.com

Gronberg, T. J., \& Reed, R. W. (1994). Estimating workers' marginal willingness to pay for job attributes using duration data. Journal of Human Resources, 29, pp. 911-931.

Haab, T. C., \& Hicks, R. L. (1997). Accounting for choice set endogeneity in random utility models of recreation demand. Journal of Environmental Economics and Management, 34, pp. 127-147.

Hagsten, E., \& Kotnik, P. (2017). ICT as facilitator of internationalization in small-and mediumsized firms. Small Business Economics, 48 (2), 431-446

Hassanuddin, N. A., Abdullah, Z., Mansor, N., \& Hassan, N. H. (2012). Acceptance towards the Use of Internet Banking Services of Cooperative Bank. International Journal of Academic Research in Business and Social Sciences, 2, pp. 135-147.

Hensher, D. A. (2006). How do respondents process stated choice experiments? Attribute consideration under varying information load. Journal of Applied Econometrics, 21, pp. 861-878.

Hensher, D. A., Rose, J. M., \& Greene, W. H. (2015). Applied Choice Analysis, second edition. Cambridge University Press, New York. 
Hu, W., Hünnemeyer, A., Veeman, M., Adamowicz, W., \& Srivastava, L. (2004). Trading off health, environmental and genetic modification attributes in food. European Review of Agricultural Economics, 31(3), pp. 389-408.

Kuhfeld, W. F., Tobias, R. D., \& Garratt, M. (1994). Efficient experimental design with marketing research applications. Journal of Marketing Research, 31(4), pp. 545-557.

Liao, Z., \& Cheung, M. T. (2002). Internet-based e-banking and consumer attitudes - an empirical study. Information \& Management, 39, pp. 283-295.

Lichtenstein, S. (2006). Understanding Consumer Adoption of Internet Banking: an Interpretive Study in the Australian Banking Context. Journal of Electronic Commerce Research, 7 , pp. 50-66.

Meijer, E., \& Rouwendal, J. (2006). Measuring Welfare Effects in Models with Random Coefficients. Journal of Applied Econometrics, 21, pp. 227-244.

Morey, E. R., Rowe, R. D., \& Watson, M. (1993). A Repeated Nested-Logit Model of Atlantic Salmon Fishing. American Agriculture Economics Association, 75, pp. 578-592.

Orme, B. K. (2010). Getting started with conjoint analysis: strategies for product design and pricing research, first edition. Research Publishers, Madison.

Padachi , K., Rojid, S., \& Seetanah, B. (2008). Investigating into the factors that influence the adoption of internet banking in Mauritius. Journal of Internet Business, 5, pp. 98-120.

Poon, W. C. (2008). Users' adoption of e-banking services: the Malaysian perspective. Journal of Business \& Industrial Marketing, 23, pp. 59-69. 
Riyadh, A., Akter, M. S., \& Islam, N. (2009). The Adoption of E-banking in Developing Countries: A Theoretical Model for SMEs. International Review of Business Research Papers, 5, pp. 212-230.

Scott, A., \& Vick, S., 1999. Patients, doctors and contracts: an application of principal-agent theory to the doctor-patient relationship. Scottish Journal of Political Economics, 46(2), pp.111134.

Shaw, W. D., \& Ozog, M. T. (1999). Modeling Overnight Recreation Trip Choice - Application of a Repeated Nested Multinomial Logit Model. Environmental and Resource Economics, 13, pp. 397-414.

Shayah, M. H., \& Qifeng, Y. (2015). Development of free zones in United Arab Emirates. In First Middle East Conference on Global Business, Economics, Finance and Banking, Dubai.

Simpson J. (2002) The impact of the Internet in banking: observations and evidence from developed and emerging markets. Telematics and Informatics, 19, pp. 315-330.

Sohail, M. S., \& Shanmugham, B. (2003). E-banking and customer preferences in Malaysia - An empirical investigation. Information Sciences, 150, pp. 207-217.

Suh, B., Han, I. (2002). Effect of trust on customer acceptance of Internet banking. Electronic Commerce Research and Application, 1(3-4), pp. 247-263.

Train, K. E. (2009). Discrete Choice Methods with Simulation, second edition. Cambridge University Press, New York. 
Vatanasombut, B., Igbaria, M., Stylianou, A. C., \& Rodgers, W. (2008). Information systems continuance intention of web-based applications customers. Information \& Management, 45, pp. 419-428.

Wengel, J. T., \& Rodriguez, E. (2006). SME Export Performance in Indonesia after the Crisis. Small Business Economics, 26, pp. 25-37.

Woldie, A., Hinson, R., Iddrisu, H., \& Boateng, R. (2008). Internet banking: an initial look at Ghanaian bank consumer perceptions. Banks and Bank Systems, 3, pp. 35-46.

World Trade Organization (2012). Trade Policy Review: United Arab Emirates. World Trade Organization, the UAE.

Yousafzai, S. Y., Pallister, J. G., \& Foxall, G. R. (2003). A proposed model of e-trust for electronic banking. Technovation, 23(11), pp. 847-860. 